\title{
I nfluência do armazenamento e da embalagem na manutenção da esterilidade do instrumental odontológico ${ }^{1}$
}

I nfluence on storage and packing to maintain the sterility of dental equipment

\section{La influencia del almacenamiento y embalaje para la conservación de laesterilidad del instrumental odontológico}

\author{
Ana Claudina Prudêncio Serratine', Claudia de Souza Gonçalves" , I sabelle Cassatti Luçolli"I
}

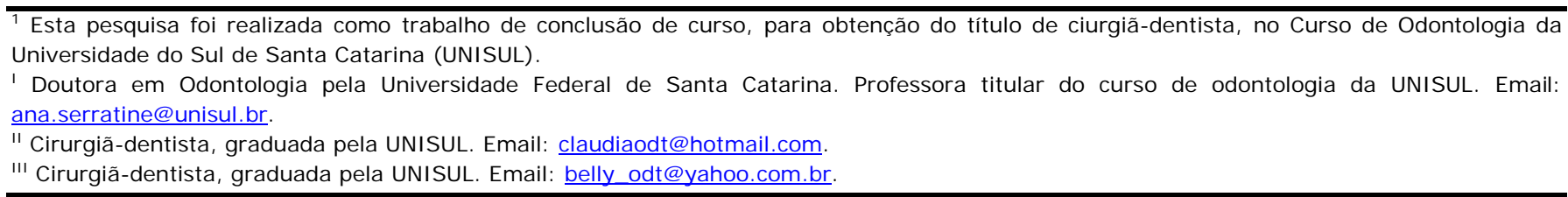

\section{RESUMO}

Este estudo teve por objetivo verificar o prazo de validade da esterilização de instrumental embalado e armazenado sob diversas condições. Foram confeccionados 395 corpos de prova metálicos, que após contaminação com Enterococcus faecalis (ATCC 19433, NEWPROV) foram subdivididos em seis grupos, compostos por 65 unidades. Cada grupo foi embalado, respectivamente, com papel Kraft, crepado, grau cirúrgico com filme, papel alumínio, tecido de algodão cru duplo e tecido tipo brim. Depois de submetidos à esterilização, os pacotes foram subdivididos, permanecendo trinta de cada tipo acondicionados em caixa plástica fechada e os demais soltos no interior do mesmo armário fechado. Após períodos de 7, 15, 30, 45, 90 e 148 dias, corpos de prova contidos em cinco pacotes de cada tipo de material de embalagem e armazenamento foram inoculados em meio de cultivo e incubados à $37^{\circ} \mathrm{C}$ por quarenta e oito horas. Após este tempo a análise microbiológica era realizada para verificar a manutenção da esterilidade dos espécimes. Todos os corpos de prova permaneceram estéreis por até 148 dias nas condições de empacotamento e armazenamento testadas. Contudo, sugere-se que as instituições de saúde realizem investigações para validar o tempo de manutenção da esterilidade dos artigos, de acordo com sua própria rotina.

Descritores: Armazenagem de produtos; Embalagem de produtos; Esterilização; Validade.

\section{ABSTRACT}

The aim of this search was to verify the expiration date of the packed and stored sterilized equipment under diverse conditions; 395 metal specimens were done and subdivided into six different groups made of 65 elements soon after being contaminated by the Enterococcus faecalis (ATCC 19433, NEWPROV). Each group was packed with Kraft paper, crepe paper, surgical-grade paper with film, aluminum paper, double raw cotton fabric and Denim. Soon after being submitted to sterilization, the packages were subdivided into thirty of each kind placed into a plastic box and then closed, while the others remained spread inside the same closed locker. After 7, 15, 30, 45, 90 and 148 days, the specimens inside the five packages of different packing materials and storage were inoculated by cultivation means and incubated at $37^{\circ} \mathrm{C}$ for forty-eight hours. After this time, microbiological analysis was carried out in order to check the sterility maintenance of the specimens. All the specimens remained sterile until the end of the experiment in the tested conditions of packing and storage. However, it is recommended to Health Institutions to develop specific studies to validate the materials' sterilization maintenance time according to their own routine.

Descriptors: Product storage; product packaging; sterilization; validation.

\section{RESUMEN}

Esta investigación tuvo como objetivo constatar la fecha de validez de la esterilización del instrumental embalado y almacenado bajo diferentes condiciones. Fueron confeccionados 395 cuerpos de prueba, metálicos, que luego de ser contaminados con Enterococcus faecalis, fueron subdivididos en seis grupos de 65 especímenes. Cada grupo fue embalado, respectivamente, con papel Kraft, papel crepado, papel quirúrgico con película, papel aluminio, tejido de algodón crudo doble y tejido brin. Sometidos a esterilización, los paquetes fueron subdivididos, permaneciendo treinta de cada tipo acondicionados en una caja plástica cerrada, el resto sueltos en el interior del mismo armario. Luego de períodos de 7, 15, 30, 45, 90 y 148 días, los cuerpos de prueba contenidos en cinco paquetes de cada tipo de material de embalaje y de almacenado, fueron inoculados en un medio de cultivo e incubados a $37^{\circ} \mathrm{C}$ durante cuarenta y ocho horas. Fue evaluado el crecimiento bacteriano para verificar la conservación de la esterilidad de los especímenes. Todos los cuerpos de prueba permanecieron estériles durante 148 días en las condiciones de envase y almacenamiento probadas. Entretanto, se sugiere que las instituciones de salud realicen investigaciones para validar el tiempo de manutención de la esterilidad de los artículos, de acuerdo con su propia rutina.

Descriptors: Almacenamiento de productos; Embalaje de productos; Esterilización; Validez. 


\section{NTRODUÇÃO}

A Odontologia iniciou como uma profissão prática e artesanal e não como uma ciência, realizando suas ações independentes dos riscos reais de infecção inerentes à sua prática ${ }^{(1)}$.

Com um aumento significativo de casos de doenças infecto-contagiosas, ocorreu a valorização da necessidade do cirurgião-dentista conhecer o risco biológico e adotar condutas para o controle da infecção durante o exercício da profissão, baseadas em protocolos de prevenção e redução da disseminação de agentes infecciosos.

Por volta do século XIX, na chamada era bacteriológica, houve uma evolução em relação aos cuidados com o material reutilizado em procedimentos invasivos. A preocupação com a disseminação de infecções durante os atendimentos cirúrgicos, levou à instituição de medidas que eliminassem os agentes infecciosos. Joseph Lister, pai da cirurgia moderna, foi o precursor no emprego das mesmas, diminuindo a mortalidade de seus pacientes tratando fios de sutura e compressas com solução de fenol. Além disso, a fervura prolongada foi utilizada rotineiramente em material e roupas até que ficou evidenciado que os microrganismos eram resistentes, demonstrando a necessidade de elevar a

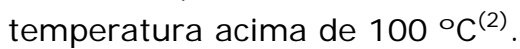

No final do século $X I X$, por meio dos trabalhos de Louis Pasteur e de Robert Koch, ficou constatada a natureza biológica dos agentes infecciosos. Foram iniciadas, então, práticas para eliminá-los das superfícies do material cirúrgico, tais como: limpeza, desinfecção e esterilização, que impedem a disseminação das infecções durante as cirurgias.

A evolução dos conhecimentos a respeito dos microrganismos patogênicos contribuiu para aperfeiçoar os processos para eliminá-los da superfície dos instrumentos odontológicos utilizados em procedimentos clínicos invasivos e não invasivos. Desta forma se chegou a uma total eliminação dos mesmos, através do processo denominado esterilização. Entretanto, para se obter e manter um instrumental estéril, outras etapas do seu processamento devem ser corretamente executadas.

O processo de esterilização permite a eliminação de todo tipo de microrganismos do instrumental que esteve em contato com secreções e sangue. Inclusive aqueles mais resistentes que estão sob a forma de esporos $^{(3)}$.

Nos consultórios odontológicos brasileiros os equipamentos mais utilizados para esterilização do instrumental são as autoclaves e os fornos de Pasteur ${ }^{(4)}$. Embora a esterilização realizada por meio do calor seco das estufas ainda seja largamente utilizada nem sempre tem um desempenho eficaz quando apresenta tempo e temperatura inadequados $^{(3-6)}$. Enquanto que as autoclaves, utilizando vapor saturado sob pressão, realizam o processo de esterilização com maior segurança, pois a destruição dos microrganismos é resultante da ação combinada de temperatura, pressão e umidade, que causam a desnaturação e termo coagulação das proteínas presentes na estrutura dos microrganismos, provocando a morte dos $\operatorname{mesmos}^{(5,7)}$.

O reprocessamento do instrumental possui etapas obrigatórias, dependentes entre si, como a lavagem, o empacotamento, a distribuição dos pacotes no interior do aparelho esterilizador, e armazenamento das embalagens estéreis. Todos os passos devem ser adequadamente aplicados, para a esterilização e manutenção da esterilidade dos instrumentos até o uso dos mesmos ${ }^{(5-10)}$.

Para a seleção da embalagem deve-se levar em consideração o tipo de equipamento que será utilizado para a realização do ciclo de esterilização( ${ }^{(5)}$. Os materiais mais utilizados na Instituição onde foi realizado o estudo, e que serão apresentados nesta pesquisa são: papel Kraft, papel grau cirúrgico com filme, tecido de algodão cru, tecido tipo brim e papel crepado para as autoclaves; e o papel alumínio e as caixas metálicas para as estufas. É importante salientar que o sistema de embalagem deve permitir além da esterilização, a manutenção da esterilidade do conteúdo até a abertura do pacote $\mathrm{e}^{(5,8-11)}$.

Após um ciclo de esterilização, realizado na rotina de um consultório odontológico, questiona-se até quando estes pacotes permanecem estéreis para o uso, garantindo a segurança para o paciente e para a equipe odontológica. $\mathrm{O}$ tipo de embalagem utilizada e forma de armazenamento dos pacotes são fatores determinantes na manutenção da esterilidade durante o tempo que os artigos estão estocados? Nas atividades diárias de um cirurgião-dentista a reutilização do instrumental é uma constante. Por isso todo o material deve ser reprocessado cuidadosamente entre os usos, a fim de impedir a disseminação de microrganismos infecciosos para os pacientes ${ }^{(3-7)}$.

Devido à existência de muita controvérsia encontrada na literatura, o presente estudo teve por objetivo estabelecer o prazo de validade da esterilização do instrumental utilizado nos tratamentos odontológicos segundo diferentes tipos de embalagens e de locais de armazenamento.

\section{MATERI AL E MÉTODOS}

Foi realizada uma investigação experimental em laboratório, para avaliar o desempenho das seguintes embalagens: papel crepado, papel Kraft, tecido de algodão cru duplo, tecido tipo Brim, envelopes de papel grau cirúrgico com filme transparente (utilizadas nas autoclaves) e lâmina de alumínio (utilizada em estufas); e a manutenção da 
esterilidade quando o material foi armazenado em armários fechados, dentro de caixas plásticas fechadas ou solto no interior dos mesmos. Estas embalagens e as condições de armazenamento citadas foram escolhidas por serem utilizadas rotineiramente pelos acadêmicos do Curso de Odontologia da Universidade do Sul de Santa Catarina (UNISUL), local onde foi executada a pesquisa. O estudo foi realizado no primeiro semestre de 2007.

Inicialmente foram selecionados 395 corpos de prova metálicos (matrizes de aço medindo $7 \mathrm{~mm}$ de largura por $15 \mathrm{~mm}$ de comprimento e $0,05 \mathrm{~mm}$ de espessura, para compor a amostra). Os corpos de prova foram contaminados por uma cepa de Enterococcus faecalis (ATCC 19433, da NEWPROV, utilizado sob a forma de discos contendo acima de $100.000 \mathrm{UFC} / \mathrm{ml}$, e utilizados segundo a orientação do fabricante), cultivada em BHI (meio de cultura contendo infuso de cérebro e coração, da HIMEDIA), na forma de cultura por 48 horas. Desta forma obteve-se uma contaminação idêntica em todos os espécimes da amostra (Figura 1).
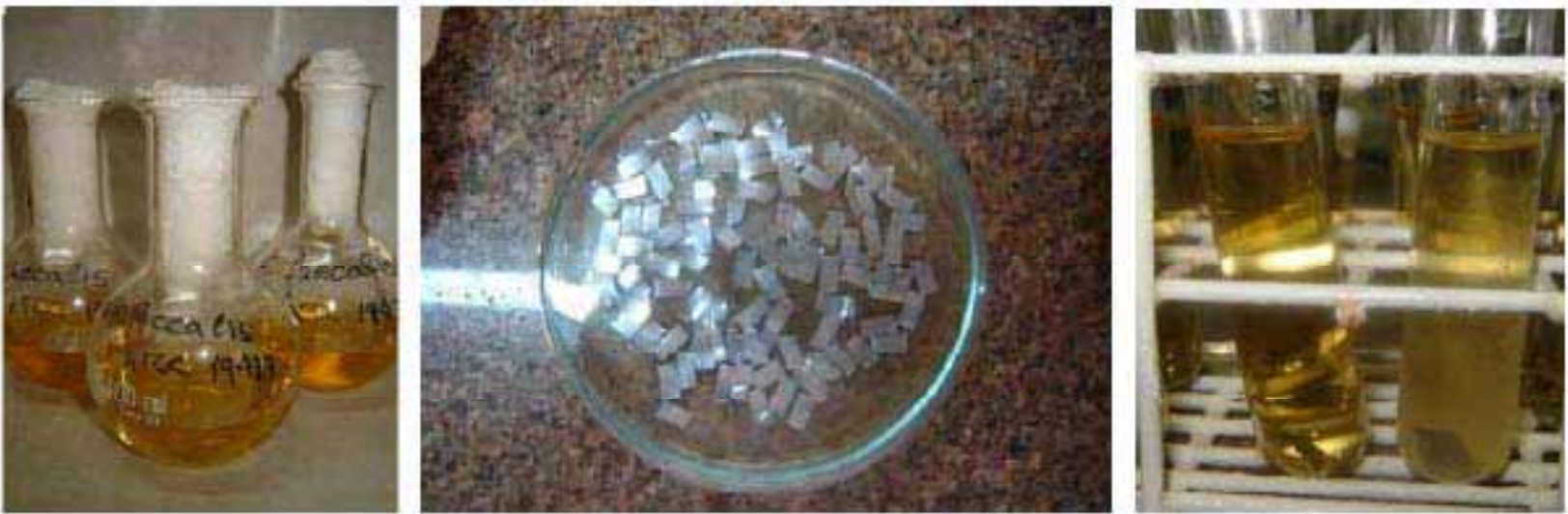

Figura 1: Contaminação padronizada dos corpos de prova

Após este período cinco corpos de prova foram novamente colocados em meio de cultura estéril (BHI) para servir como controle positivo, sendo levados para estufa de cultura a $37^{\circ} \mathrm{C}$ por 24 horas. A turvação do meio confirmou a contaminação dos corpos de prova.

Os demais 390 corpos de prova foram embalados em pacotes dos diferentes materiais: papel crepado, papel Kraft, tecido de algodão cru duplo, tecido tipo "Brim", envelopes de papel grau cirúrgico com filme transparente e lâmina de alumínio. Portanto sessenta e cinco pacotes de cada tipo de embalagem foram esterilizados. Vale ressaltar que as embalagens eram provenientes de diversos fornecedores e as de tecido eram novas e foram previamente lavadas (Figura 2).

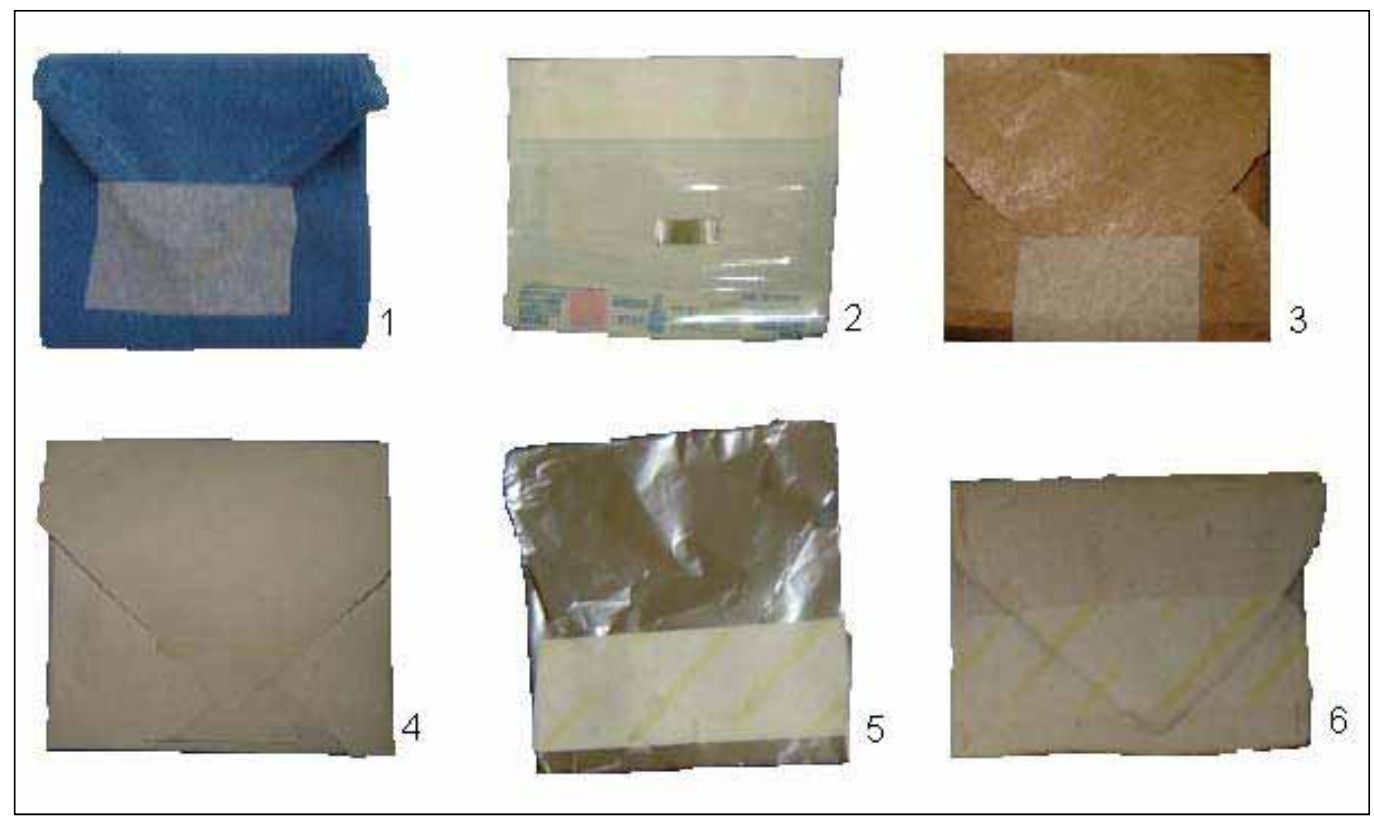

Figura 2: Embalagens dos corpos de prova que compunham a amostra. 1. Tecido tipo Brim; 2. Papel grau cirúrgico; 3. Papel Kraft; 4. Papel crepado; 5. Lâmina de alumínio; 6. Tecido de algodão cru (campo duplo). 
O empacotamento foi realizado no interior de uma Capela Microbiológica, do Laboratório de Microbiologia da Universidade do Sul de Santa Catarina (UNISUL), utilizando-se pinças estéreis e envelopes dos diversos tipos de materiais de embalagens já citados, e selados com a fita indicadora de temperatura. As pesquisadoras estavam devidamente paramentadas e utilizaram luvas de látex estéreis durante todas as etapas do trabalho laboratorial.

A seguir, os pacotes de papel crepado, papel grau cirúrgico, papel Kraft, tecido de algodão cru duplo, tecido tipo "Brim" e envelopes de papel grau cirúrgico com filme transparente foram levados à autoclave. Já os pacotes de lâmina de alumínio foram encaminhados à estufa. Os equipamentos de esterilização (estufa e autoclave) tiveram seus ciclos devidamente monitorados por indicadores biológicos (Bacillus subtilis e Bacillus stearothermophilus, respectivamente) e respeitaram parâmetros físicos recomendados na literatura, isto é, para a efetividade do processo de esterilização, na estufa foi utilizado um processamento de 1 hora à temperatura de $170 \circ \mathrm{C}$ e na autoclave um ciclo de 20 minutos à temperatura de $121^{\circ} \mathrm{C}$ e sob pressão de 15 libras $^{(5-7)}$.

Após a esterilização, 360 pacotes, 60 de cada tipo de embalagem, foram armazenados em um mesmo armário fechado. Destes pacotes 180 (30 de cada tipo de embalagem) no interior de uma caixa plástica fechada, e os outros 180 soltos. Utilizou-se um dos armários usados pelos alunos do Curso de Odontologia, onde os materiais dos mesmos são guardados. $\mathrm{O}$ armário, que ficava à $30 \mathrm{~cm}$ do chão ${ }^{(7)}$, era aberto cinco vezes ao dia, durante os horários em que havia fluxo de pessoas no ambiente, deixado aberto em torno de cinco minutos em cada ocasião, para simular em parte o que ocorre na atividade real de um consultório odontológico.

Cinco pacotes de cada tipo de embalagem foram encaminhados, imediatamente após o ciclo de esterilização, para o Laboratório de Microbiologia da UNISUL para servirem como controle negativo.
Foram devidamente processados da seguinte forma: no interior da Capela Microbiológica os pacotes foram abertos próximos à chama do Bico de Bunsen, os corpos de prova removidos com o auxílio de uma pinça flambada ao rubro, e colocados em tubos de ensaio, identificados, contendo o meio de cultura líquido (BHI) estéril. Este meio de cultura foi escolhido por ser rico em nutrientes, facilitar o crescimento bacteriano e ser translúcido. Esta propriedade facilita a verificação do crescimento bacteriano, que é identificado pela turvação do meio de cultura (Figura 1). Após esta etapa, os tubos de ensaio contendo os corpos de prova foram acondicionados em Jarras de Gaspak e colocados dentro da Estufa Microbiológica a $377^{\circ} \mathrm{C}$ e permaneceram 48horas. Os indicadores biológicos utilizados durante a esterilização foram, também, incubados segundo as orientações do fabricante. Durante a execução destes procedimentos foram respeitadas todas as normas para manutenção da assepsia.

Após períodos de 7 dias, 15 dias, 30 dias, 45 dias, 90 dias e 148 dias, cinco pacotes de cada tipo de material de embalagem presente no interior da caixa plástica fechada, e cinco pacotes de cada tipo de material de embalagem solto no armário, foram levados ao Laboratório de Microbiologia da UNISUL, onde no interior da Capela Microbiológica foram processados como os pacotes que serviram de controle negativo.

Após o período de incubação, foi realizada a leitura de cada amostra, observando e registrando a ocorrência de crescimento bacteriano ou não.

\section{RESULTADOS}

Todos os espécimes avaliados imediatamente após o processo de esterilização não apresentaram crescimento bacteriano, comprovando que todos os tipos de embalagem permitiram a esterilização (Quadro 1). Este teste microbiológico, realizado no tempo zero, demonstrou a esterilização dos corpos de prova.

Quadro 1: Resultado do crescimento bacteriano nos corpos de prova acondicionados nos diversos tipos de embalagens, imediatamente após os ciclos de esterilização. Tubarão, SC, 2007.

\begin{tabular}{|c|c|c|c|c|c|c|}
\cline { 2 - 7 } \multicolumn{1}{c|}{} & \multicolumn{6}{c|}{ Tipo de embalagem } \\
\cline { 2 - 7 } \multicolumn{1}{c|}{} & Algodão Cru & "Brim" & $\begin{array}{c}\text { Papel } \\
\text { crepado }\end{array}$ & $\begin{array}{c}\text { Papel grau } \\
\text { cirúrgico }\end{array}$ & Papel kraft & $\begin{array}{c}\text { Papel } \\
\text { Alumínio }\end{array}$ \\
\hline $\begin{array}{c}\mathbf{N}^{\circ} \text { de Espécimes } \\
\begin{array}{c}\text { Crescimento } \\
\text { bacteriano }\end{array}\end{array}$ & 5 & 5 & 5 & 5 & 5 & 5 \\
\hline
\end{tabular}

Nenhum dos espécimes armazenados, estando acondicionado dentro da caixa ou solto dentro do armário (Quadro 2) apresentou crescimento bacteriano, nos tempos estabelecidos pela pesquisa.
Portanto, a esterilidade dos corpos de prova até cento e quarenta e oito dias foi mantida, independente do material da embalagem e da forma de armazenagem. 
Quadro 2: Resultado do crescimento bacteriano nos corpos de prova acondicionados em diferentes embalagens e mantidos nos dois tipos de armazenamento, segundo o tempo de estocagem. Tubarão, SC, 2007.

\begin{tabular}{|c|c|c|c|c|}
\hline $\begin{array}{c}\text { Tipo de } \\
\text { Embalagem }\end{array}$ & $\begin{array}{c}\text { Espécimes soltos } \\
\text { no armário }\end{array}$ & $\begin{array}{l}\text { Espécimes dentro de } \\
\text { caixa no armário }\end{array}$ & $\begin{array}{c}\text { Tempo de } \\
\text { estocagem (dias) }\end{array}$ & $\begin{array}{c}\text { Crescimento } \\
\text { Bacteriano }\end{array}$ \\
\hline \multirow{6}{*}{ Algodão Cru } & 5 & 5 & 7 & Negativo \\
\hline & 5 & 5 & 15 & Negativo \\
\hline & 5 & 5 & 30 & Negativo \\
\hline & 5 & 5 & 45 & Negativo \\
\hline & 5 & 5 & 90 & Negativo \\
\hline & 5 & 5 & 148 & Negativo \\
\hline \multirow{6}{*}{ Tecido tipo "brim" } & 5 & 5 & 7 & Negativo \\
\hline & 5 & 5 & 15 & Negativo \\
\hline & 5 & 5 & 30 & Negativo \\
\hline & 5 & 5 & 45 & Negativo \\
\hline & 5 & 5 & 90 & Negativo \\
\hline & 5 & 5 & 148 & Negativo \\
\hline \multirow{6}{*}{ Papel Crepado } & 5 & 5 & 7 & Negativo \\
\hline & 5 & 5 & 15 & Negativo \\
\hline & 5 & 5 & 30 & Negativo \\
\hline & 5 & 5 & 45 & Negativo \\
\hline & 5 & 5 & 90 & Negativo \\
\hline & 5 & 5 & 148 & Negativo \\
\hline \multirow{6}{*}{$\begin{array}{l}\text { Papel Grau } \\
\text { Cirúrgico }\end{array}$} & 5 & 5 & 7 & Negativo \\
\hline & 5 & 5 & 15 & Negativo \\
\hline & 5 & 5 & 30 & Negativo \\
\hline & 5 & 5 & 45 & Negativo \\
\hline & 5 & 5 & 90 & Negativo \\
\hline & 5 & 5 & 148 & Negativo \\
\hline \multirow{6}{*}{ Papel Kraft } & 5 & 5 & 7 & Negativo \\
\hline & 5 & 5 & 15 & Negativo \\
\hline & 5 & 5 & 30 & Negativo \\
\hline & 5 & 5 & 45 & Negativo \\
\hline & 5 & 5 & 90 & Negativo \\
\hline & 5 & 5 & 148 & Negativo \\
\hline \multirow{6}{*}{ Papel Alumínio } & 5 & 5 & 7 & Negativo \\
\hline & 5 & 5 & 15 & Negativo \\
\hline & 5 & 5 & 30 & Negativo \\
\hline & 5 & 5 & 45 & Negativo \\
\hline & 5 & 5 & 90 & Negativo \\
\hline & 5 & 5 & 148 & Negativo \\
\hline
\end{tabular}

É importante salientar que todos os pacotes se mantiveram íntegros.

\section{DISCUSSÃO}

O acondicionamento de artigos deve receber atenção especial, pois o reprocessamento do material ocorre dentro de uma seqüência de etapas até o momento do uso, devendo ser tomados cuidados em todas elas ${ }^{(2)}$.

Vários fatores, inclusive a qualidade da embalagem, influenciam na validade da esterilização.
O tipo de invólucro é o principal fator que determina o tempo em que os artigos estocados mantêm a esterilidade. Assim, a escolha do material das embalagens deve ser cuidadosa ${ }^{(8)}$, levando em consideração os parâmetros de custo e qualidade ${ }^{(2,7,11)}$.

Os corpos de prova esterilizados em embalagens de tecido de algodão cru, nesta pesquisa, permaneceram estéreis por 148 dias nos dois tipos de armazenamento. Salienta-se que os tecidos foram lavados na véspera e eram campos novos e duplos. 
Apesar de ser um dos materiais mais utilizados na prática hospitalar, estudo ${ }^{(12)}$ comprovou, que este material de empacotamento pode ser utilizado com segurança, enquanto novo, como barreira microbiológica. Entretanto não deve ser submetido a reprocessamentos que excedam a sessenta e cinco ciclos, para garantir sua eficácia contra contaminação.

Apesar do bom resultado demonstrado por este material, semelhante aos achados em estudo recente ${ }^{(13)}$, que verificou a manutenção de esterilidade de materiais empacotados por até 25 dias, existe concordância na literatura em relação à falta de segurança da embalagem de tecido no que diz respeito à barreira bacteriana, que pode ser nula ou muito baixa, com eficiência de filtração de apenas $34 \%$ para o algodão e de $99,9 \%$ para os papéis ${ }^{(14)}$. Existem vários problemas que atrapalham a qualificação do tecido de algodão como embalagem, tais como a pequena barreira microbiana e as repetidas lavagens que causam a ruptura das fibras têxteis, além dos desgastes e furos, sendo difícil avaliar a quantidade máxima de reprocessamentos possíveis. Essas situações não são vivenciadas quando se utilizam materiais descartáveis, a exemplo do não-tecido e dos papéis crepado e grau cirúrgico ${ }^{(14)}$.

Assim como o algodão cru (duplo), o tecido tipo "Brim" obteve o mesmo resultado, apesar de não ser um campo duplo, podendo ser uma alternativa de embalagem de tecido menos dispendiosa. Salienta-se que o tecido foi previamente lavado para a confecção das embalagens. Vale ainda ressaltar que os custos com as embalagens de tecido, independente do tipo, possuem gastos que vão além de sua confecção, como os de lavanderia. Embora este material não esteja indicado pelas normas da $\operatorname{ANVISA}^{(7)}$, ele foi testado por ser utilizado na Instituição de Ensino onde a pesquisa foi realizada, demonstrando que na condição de uso utilizada na pesquisa ele é tão eficaz quanto o algodão cru (duplo).

Os corpos de prova esterilizados em embalagens de papel Kraft permaneceram estéreis até o fim da pesquisa, apesar deste material ser muito criticado pela literatura consultada devido ao efeito memória, irregularidades na gramatura com presença de micro furos, resistência física frágil e barreira microbiana vulnerável após o processo de esterilização(10). Estas desvantagens, comparadas as de outros tipos de papéis, levaram ao quase desuso deste material, porém é importante levar em consideração que ele tem um custo mais baixo e pode ser uma alternativa de uso em serviços públicos ou para contenção de despesas. Um estudo realizado ${ }^{(4)}$ mostra que nos cursos de Odontologia das Instituições Públicas brasileiras ele ainda é um dos materiais usado rotineiramente, sendo importante o conhecimento de sua eficácia quando manuseado e armazenado de forma adequada

As embalagens de papel crepado que também mantiveram a esterilidade dos corpos de prova por 148 dias apresentam muitas vantagens, de acordo com alguns pesquisadores ${ }^{(2,11)}$, sendo 0 papel crepado um tipo de embalagem desenvolvida para ser uma alternativa ao tecido de algodão. Possui características tais como: produto atóxico e flexível podendo ser utilizado para confecção de campos cirúrgicos e aventais, possui barreira efetiva contra a penetração de microorganismos, pode ser utilizada para esterilização a vapor d água saturada e óxido de etileno e resiste a temperaturas de até 150 o $\mathrm{C}$ por 1 hora.

A grande vantagem da utilização deste tipo de embalagem é que possui barreira bacteriana acima de $90 \%$, são descartáveis, e contribui para uma menor taxa de retrabalho para o Centro de Esterilização ${ }^{(9-10,15-16)}$. Além disto, é de fácil manuseio quando comparado ao Kraft.

Existem diversos fatores que podem influenciar na determinação de um prazo seguro para a manutenção da esterilidade, como: a eficiência do empacotamento, a intensidade de manuseio dos pacotes e as condições de transporte e estoque ${ }^{(13)}$. Este estudo ratificou a importância das orientações da ANVISA ${ }^{(7)}$ “... para garantir a esterilidade dos artigos empacotados eles devem ser armazenados em área seca, longe de umidade, em armários com portas e não devem ser dobrados ou amassados. Na distribuição dos pacotes esterilizados deve-se ter o cuidado de manipulá-los com mãos limpas, com cuidado e o mínimo possível." Todos estes cuidados foram executados no decorrer da pesquisa garantindo a integridade de todas as embalagens avaliadas. Ainda segundo a ANVISA (7) "Cada serviço deve realizar a validação do processo de esterilização dos artigos recorrendo a testes laboratoriais de esterilidade, considerando os tipos de embalagens utilizadas, os métodos de esterilização, as condições de manuseio e locais de armazenamento". Portanto, há a necessidade das instituições estabelecerem seu prazo de validade dentro da sua realidade e com base científica, já que a maioria segue prazos obtidos de forma empírica ou copiados. Desta forma existe a possibilidade de se adequar a um tipo de invólucro que atenda às necessidades dos serviços. Por isso escolheu-se trabalhar com os tipos de embalagens utilizadas no Curso de Odontologia da UNISUL, oferecendo duas opções de forma de armazenamento, que podem ser empregadas sem problemas nesta Instituição.

Ao realizar este estudo pretendeu-se estabelecer uma prática que fosse segura para o atendimento prestado aos pacientes, assim como evitar o tempo e os gastos com o reprocessamento de instrumental 
que ainda se mantem estéril. Na prática da Odontologia alguns instrumentos são utilizados diariamente, como por exemplo: espelhos, pinças, sondas exploradoras, curetas; enquanto outros são de uso esporádico como fórceps especiais, cinzéis, martelos entre outros. Quando se submete um instrumento à esterilização, ele tem que ser lavado, seco e embalado para então ser submetido ao processo de esterilização. Por isso a manutenção dos pacotes com o instrumental estéril por períodos mais prolongados facilita a rotina e reduz gastos do consultório odontológico. No caso da instituição de ensino, na qual o estudo foi realizado, setenta consultórios funcionam 12 horas por dia, assim a utilização dos resultados da pesquisa teve um grande impacto positivo.

Esta questão do tempo que os artigos esterilizados podem permanecer estocados pode ser vista como um componente econômico de grande importância, pois menores prazos têm maiores custos, relacionados ao consumo de insumos como: mão de obra, embalagem, invólucros, fitas adesivas, fitas indicadoras do processo de esterilização, consumo do equipamento esterilizador e desgaste dos artigos reprocessados ${ }^{(2,14)}$.

\section{CONCLUSÃO}

Após períodos de 7, 15, 30, 45, 90 e 148 dias, não houve crescimento bacteriano nos corpos de prova empacotados com papel crepado, papel grau cirúrgico com filme, papel Kraft, tecido de algodão cru, tecido tipo "Brim" e papel alumínio. Todos permaneceram estéreis nas condições de armazenamento testadas.

Os resultados do estudo podem ser aplicados na Instituição na qual foi realizado, a fim de facilitar a rotina da sua Central de Esterilização.

Sugere-se, por isso que as instituições de saúde realizem novas investigações, de acordo com as suas rotinas de empacotamento e armazenamento dos artigos estéreis, a fim de otimizarem o tempo e os custos operacionais gastos, garantindo ao mesmo tempo a esterilidade dos artigos e a segurança do seu uso.

\section{REFERÊNCI AS}

1. Rabello SB, Godoy CVC, Dos Santos FRW. Presença de Bactérias em Instrumentais e Superfícies do Ambiente Clínico Odontológico. Revista Brasileira de Odontologia. 2001;58(3):184-18.

2. Brito FP, Galvão CM, Françolin L, Rotta CSG. Validação do processo de esterilização de artigos médico-hospitalares segundo diferentes embalagens. Rev Bras Enferm. 2002; 55(4):414-19.

3. Serratine ACP, Rocha MJC. Avaliação da Esterilização Realizada por Meio de Estufas (Forno de
Pasteur) em consultórios odontológicos da grande Florianópolis. Revista Alcance. 1998;5(4):53-8.

4. Sasamoto SAA, Tipple AFV, Souza ACS, Paiva EMMP, Souza CP, Pimenta FC. Evaluation of central supply units in public dental medicine colleges in Brasil. Braz J Infect Dis. 2004;8(6):445-53.

5. Teixeira M, Santos MV. Responsabilidade no Controle de Infecção. Revista da Associação Paulista de Cirurgiões Dentistas. 1999;53(3)117-189.

6. Tavares SSFT, Sousa JT, Tipple AFV, Souza ACS, Pimenta FC, Anders PS. Eficácia da estufa de Pasteur como equipamento esterilizante em consultórios odontológicos. Rev. esc. enferm. USP. 2008; 42(1): 160-167.

7. Agência Nacional de Vigilância Sanitária (ANVISA), Ministério da Saúde. Serviços odontológicos: prevenção e controle de riscos. Brasília (Brasil): ANVISA, 2006.

8. Januzelli JLL. Materiais de embalagem no processo de esterilização por óxido de etileno. Revista Enfoque. 1991; 19(4):6-10.

9. Santos IBC, Oliveira TL, Nogueira MJ F. A embalagem para esterilização sob a ótica assistencial do enfermeiro. Revista SOBECC. 2002; 7(1):7-21.

10. Pellizzeti N. Esterilização: práticas recomendadas. Revista SOBECC. 1999; 4(1) 14-19.

11. Graziano KU. Embalagem de artigos odontomédico hospitalares. In: Lacerda RA. Controle de infecção em centros cirúrgicos: fatos, mitos e controvérsias. São Paulo: Atheneu, 2003. p.197-211. 12. Rodrigues $E$, Levin AS, Sinto SI, Mendes CF, Barbosa B, Graziano KU. Evaluation of the use and re-use of cotton fabrics as medical and hospital wraps. Braz. J. Microbiol. 2006;37(2): 113-116.

13. Neves ZCP, Melo DSM, Souza ACS, Tipple AFV, Rodrigues MAV. Artigos esterilizados em calor úmido: validação do sistema de guarda. Rev Bras Enferm. 2004;57(2): 152-156.

14. Longui LF. Cuidados e alternativas para embalagens de esterilização. Revista SOBECC. 1997; 2(2): 14.

15. Costa EAM. Estudo de custo-benefício de embalagens para esterilização. Revista SOBECC. 2004; 9(3): 38-43.

16. Possari JF. Embalagens [Internet]. São Paulo: Internet Group do Brasil S.A. (iG); 2006 [update 2006 may 22; cited 2009 mar 10]. Available from: http://www.joaopossari.hpg.ig.com. br/embalagens.htm.

Artigo recebido em 20.11.07.

Aprovado para publicação em 31.03.09. 